\title{
ELEFANTES E INTERVENCIÓN HUMANA EN LOS YACIMIENTOS DEL PLEISTOCENO INFERIOR Y MEDIO DE ÁFRICA Y EUROPA
}

\author{
ELEPHANTS AND HUMAN INTERVENTION \\ IN THE LOWER AND MIDDLE PLEISTOCENE \\ SITES OF AFRICA AND EUROPE
}

“... principio de una novela, empezar el tema en cualquier parte, para tener ganas de terminarlo, comenzar con frases bellísimas..."

(BAUdelaire)

\section{JUAN ANTONIO MARTOS ROMERO}

$(*)$

\section{RESUMEN}

En el presente artículo se revisan yacimientos africanos y europeos donde se ha planteado la existencia de una intervención humana sobre elefantes. Se establece una diferencia entre sitios con un sólo individuo (tipo 1) o un número alto de elefantes (tipo 2). Con independencia del carácter de la intervención humana, cuando ésta es evidente, tales diferencias responden a unos procesos de formación distintos con problemáticas singulares que condicionan finalmente la capacidad informativa del yacimiento.

\begin{abstract}
In this paper, we review some African and European sites at which it is claimed that elephants were exploted by humans. The differences between sites with only one individual (type 1) and sites with a large number of elephants (type 2) are related to different formation processes and particular problems which limit the informative potential of sites.
\end{abstract}

(*) Becario Predoctoral del Departamento de Prehistoria e Historia Antigua de la Universidad Nacional de Educación a Distancia. Avda. Senda del Rey s/n, 28040 Madrid.

El artículo fue remitido en su versión final el 16-I-98.
Palabras clave: Pleistoceno Inferior. Pleistoceno medio. Elefantes. Proceso de formación. Intervención humana. Explotación de carcasas. Obtención de carcasas.

Key words: Lower Pleistocene. Middle Pleistocene. Elephants. Process of formation. Human intervention. Exploitation of the carcasses. Acquisition of the carcasses.

\section{INTRODUCCIÓN}

Con la reanudación en el verano de 1993 de las excavaciones en los conocidos yacimientos de Torralba y Ambrona (Soria) dentro de un proyecto de investigación iniciado en 1990, surgió la posibilidad de efectuar una revisión bibliográfica de aquellos sitios donde se ha planteado la existencia de una interacción entre grupos humanos y elefantes (1). Pensamos que un trabajo de tales características permitiría reunir un volumen de información hasta ese momento dispersa, que, contemplada desde una perspectiva crítica, pudie-

(1) El artículo aquí presentado es un resumen del trabajo de investigación leído en noviembre de 1995 en el Dpto. de Prehistoria e Historia Antigua de la U.N.E.D. con el mismo título y está encuadrado dentro del proyecto Estudio y excavación de los yacimientos pleistocenos de Ambrona y Torralba (Soria) bajo la dirección de los doctores Manuel Santonja Gómez y Alfredo Pérez González. 
ra aportar luz a las controvertidas interpretaciones que rodean este tipo de yacimientos, de las que, precisamente, son un claro exponente Torralba y Ambrona, mantenidos en la bibliografía más generalizada e internacional como ejemplos de cazaderos pleistocenos de elefantes.

Bajo estas premisas se juzgó conveniente acotar, desde un principio, el marco cronológico y geográfico al Pleistoceno inferior y medio de África y Europa. El resultado fue la recopilación de cerca de una treintena de yacimientos, centrándose el presente artículo en las principales conclusiones obtenidas de su revisión crítica (Tab. 1).
Pese a la amplitud espacio-temporal del marco elegido, la principal dificultad a la hora de manejar los datos aportados por cada yacimiento fue la disparidad de los mismos como consecuencia de los diferentes criterios de excavación y planteamientos teóricos que han animado los sucesivos paradigmas científicos imperantes en la investigación a lo largo del siglo. Debido a ello, la información disponible se muestra muy desigual en aspectos tan variados como la estratigrafía, el proceso de sedimentación y formación de los sitios, o los análisis tafonómicos, hoy por hoy imprescindibles para proponer con un mínimo de ri-

\begin{tabular}{|c|c|c|}
\hline Yacimiento & Cronología* & Fuente \\
\hline Barogali & 1,6-1,3 (ESR) & Chavaillon et alii, 1987 \\
\hline Mwanganda & $(\mathrm{Pm})$ & Clark y Haynes, 1970 \\
\hline FLK N6 & $1,8-1,7(\mathrm{~K} / \mathrm{Ar})$ & Leakey, M., 1971 \\
\hline Deinotherium site & $(\mathrm{Pi})$ & Leakey, M., 1971 \\
\hline Olorgesailie & $0,99\left({ }^{40} \mathrm{Ar}^{-39} \mathrm{Ar}\right)$ & Potts, 1989 \\
\hline Gesher Benot Ya'aqov & $(\mathrm{Pm})$ & Goren-Inbar et alii, 1992 \\
\hline Clacton On Sea & $(\mathrm{Pm})$ & Singer et alii, 1973 \\
\hline La Cotte de Saint-Brelade & 0,128 (estadio 5e) & Callow, 1986 \\
\hline Kärlich-Seeufer & $0,396\left({ }^{40} \mathrm{Ar}-{ }^{39} \mathrm{Ar}\right)$ & Kröger et alii, 1988 \\
\hline Bilzingsleben & $\begin{array}{l}0,32-0,35\left({ }^{234} \mathrm{U}-{ }^{230} \mathrm{Th}\right) \\
0,414-0,28 \text { (ESR) }\end{array}$ & Mania, 1988 \\
\hline Ehringsdorf & $0,224-121\left({ }^{234} \mathrm{U}-{ }^{230} \mathrm{Th}\right)$ & Brunnacker et alii, 1983 \\
\hline Lehringen & $(\mathrm{Pm})$ & Müller-Beck, 1982 \\
\hline Venosa Notarchirico & $(\mathrm{Pm})$ & Lefèvre et alii, 1994 \\
\hline La Polledrara di Cecanibbio & $\begin{array}{l}0,45 \pm 0,12 \text { (Racemización) } \\
0,186 \text { (ESR) } \\
0,43 \text { (K-Ar) ? } \\
\end{array}$ & \begin{tabular}{|l|} 
Anzidei et alii, 1989 \\
Everden y Curtis, 1965 \\
\end{tabular} \\
\hline Isernia La Pineta & $\begin{array}{l}0,736(\mathrm{~K}-\mathrm{Ar}) \\
0,68(\mathrm{~K}-\mathrm{Ar}) \\
0,73(\mathrm{~K}-\mathrm{Ar}) \\
0,545(\text { Racemización) } \\
0,5 \text { (Arvicola terrestris cantiana) }\end{array}$ & $\begin{array}{l}\text { Delitala et alii, } 1983 \\
\text { Sevnik } \text { et alii, } 1981 \\
\text { Belluomi, } 1985 \\
\text { Roebroeks y Kolfschoten, } 1994\end{array}$ \\
\hline Fontana Rannucio & $0,458-0,366(\mathrm{~K}-\mathrm{Ar})$ & Biddittu et alii, 1979 \\
\hline Cava Pompi & $0,4(\mathrm{~K}-\mathrm{Ar}) ?$ & Biddittu y Segre, 1978 \\
\hline Torre in Pietra & $0,4(\mathrm{~K}-\mathrm{Ar}) ?$ & Piperno y Biddittu, 1978 \\
\hline Castel di Guido & $(\mathrm{Pm})$ & Guidi y Piperno, 1992 \\
\hline Rebibbia di Casal de' Pazzi & $(\mathrm{Pm})$ & Anzidei y Ruffo, 1985 \\
\hline Cúllar de Baza I & $0,9-0,7$ (microfauna) & Ruiz Bustos, 1984 \\
\hline Solana del Zamborino & $(\mathrm{Pm})$ & Ruiz Bustos et alii, 1986 \\
\hline Arriaga II & $(\mathrm{Pm})$ & Rus y Vega, 1984 \\
\hline Áridos 1 & $(\mathrm{Pm})$ & Santonja et alii, 1980 \\
\hline Áridos 2 & $(\mathrm{Pm})$ & Santonja et alii, 1980 \\
\hline San Isidro & $(\mathrm{Pm})$ & Paz de Graells, 1897 \\
\hline Transfesa & $(\mathrm{Pm})$ & Meléndez y Aguirre, 1958 \\
\hline La Aldehuela & $(\mathrm{Pm})$ & \\
\hline Torralba & $(\mathrm{Pm})$ & \begin{tabular}{|l|} 
Howell, 1962 \\
\end{tabular} \\
\hline Ambrona & $(\mathrm{Pm})$ & Howell et alii, 1995 \\
\hline
\end{tabular}

Tab. 1. Cronología de los yacimientos citados en el texto (cuando ha sido posible se cita método de datación y fuente).

* En millones de años B.P.

Con $(\mathrm{Pm})$ y $(\mathrm{Pi})$ se indica que el sitio está situado cronológicamente en el Pleistoceno medio o inferior sin que existan dataciones númericas publicadas hasta la fecha.

? La correlación entre los sedimentos datados y el nivel arqueológico no es clara a nuestro juicio.

T. P., 55, n. $^{\circ} 1,1998$ 
gor interpretaciones finales. Con todo, intentamos que la revisión crítica pudiera ser enfocada en cada yacimiento con unos criterios y objetivos similares, capaces de ofrecer conclusiones interesantes y válidas. Así, se prestó especial atención a aquellos elementos que pudieran hacer referencia a cuestiones que previamente habíamos considerado como esenciales, fundamentalmente el contexto estratigráfico y la dinámica de formación del sitio, junto a la relación entre los diferentes restos.

Con estos condicionantes se analizaron las conclusiones establecidas para cada yacimiento y su coherencia, partiendo exclusivamente de la comprensión crítica de los argumentos esgrimidos por los excavadores, ya que nuestro trabajo se limitó al material bibliográfico generado por los sitios. De esta manera, se evaluó si estabamos o no en presencia de suelos de ocupación y, lo que es mucho más importante en la mayor parte de los casos, se estimó la capacidad informativa del yacimiento. Por último, desde esta posición y siempre que fue posible, se valoró la consistencia de las diversas interpretaciones acerca del tipo de actividad antrópica o impacto de la intervención humana, cuando ésta existió.

\section{YACIMIENTOS}

Una vez examinados los sitios bajo este criterio resultó obvio que, al menos, podía establecerse una división inicial entre dos tipos de yacimientos que simplemente definiremos como 1 y 2 . Esta notación es utilizada aquí con un sentido similar al empleado en yacimientos africanos (tipo B y C) (Isaac, 1978; 1984) y fundamentalmente al ya apuntado por otros autores a la hora de recalcar diferencias entre sitios con restos de elefantes (Santonja, 1992). Debido a la disparidad en la información y en parte también a la idiosincrasia de los sitios, una gran parte no encaja de forma clara en uno u otro grupo. No obstante, consideramos que tal distinción era bien significativa pues permitía establecer importantes diferencias entre aquéllos que sí podían ser definidos con precisión en una u otra categoría.

Las diferencias que hemos observado al profundizar en ambos tipos tienen, a nuestro juicio, una clara relación con procesos de formación distintos y con problemáticas singulares que trataremos de sistematizar valorando el alcance de la información proporcionada por los excavadores.
Por ello, cobran un papel fundamental en su estudio los aspectos sedimentarios y tafonómicos que nos permitan establecer qué capacidad informativa contienen y de qué tipo, antes de plantearnos interpretaciones relacionadas con el comportamiento subsistencial como resultado de la posible intervención de grupos humanos sobre elefantes. Éstas, han ido desde la aceptación de episodios de caza, al desarrollo de estrategias de carroñeo más o menos marginales o actividades puntuales de despedazado y adquisición de recursos; a las que se han otorgado un grado de organización y planificación muy variable según los momentos y excavadores. En realidad, la representación de uno de estos escenarios del pasado debería pasar por tres vías de interpretación; una que nos permita discriminar que factores antrópicos y/o no antrópicos han intervenido en la formación del sitio (tafonómica), una segunda centrada en la reconstrucción de las actividades efectuadas por los grupos (arqueológica) y, por último, una lectura atenta de aquellos elementos relacionados con el comportamiento de los taxones representados (paleoecológica) que puedan haber incidido en factores como el emplazamiento del yacimiento o las causas de muerte de los individuos, entre otros.

\section{Tipo 1}

Sitios caracterizados por el hallazgo de restos atribuidos a un único elefante y presencia de industria lítica asociada, en la mayor parte de los casos, en relación estricta con los restos óseos. Estos yacimientos, generalmente, se distinguen también por una escasa diversidad taxonómica.

Entre los revisados situamos en el tipo 1 los siguientes: Barogali (República de Djibouti); Mwanganda (Malawi); Olorgesailie 15 (Kenya); Lehringen (Alemania); Venosa Notarchirico (Italia); Arriaga y Áridos I y II (España).

\section{Tipo 2}

Sitios caracterizados por acumulaciones importantes de restos pertenecientes a más de un elefante e incluso a otros taxones que pueden superar en número de individuos a los primeros. $\mathrm{La}$ contemporaneidad y asociación de piezas líticas, y fundamentalmente la existencia de una relación estricta entre éstas y los huesos, resulta casi siem- 
pre controvertida o en todo caso difícil de contrastar.

En el tipo 2 hemos incluido: La Cotte de SaintBrelade (Reino Unido); Kärlich-Seeufer (Alemania); La Polledrara di Cecanibbio, Isernia La Pineta, Castel di Guido, Rebibbia-Casal de'Pazzi (Italia) y Ambrona (España).

El resto de yacimientos hasta alcanzar un total de 30 no pueden, a nuestro modo de ver, encuadrarse de forma categórica en uno u otro tipo, bien por sus características o porque la información disponible es escasa o inexistente en cuestiones esenciales. Si tomamos como criterio principal el número mínimo de elefantes quedarían repartidos de la siguiente manera:

- Un único o escasos individuos: FLK North 6 (Olduvai, Tanzania); Deinotherium Site (Olduvai, Tanzania); Gesher Benot Ya'aqov (Israel); Cúllar de Baza I; San Isidro (Tejar de las Ánimas); Transfesa y La Aldehuela (España).

- Un número alto de elefantes: Clacton On Sea (Reino Unido); Bilzingsleben, Ehringsdorf (Alemania); Solana del Zamborino, Torralba (España); Fontana Rannucio, Cava Pompi y Torre in Pietra (Italia).

\section{Yacimientos tipo 1}

Pese al amplio marco cronológico y dispersión geográfica, presentan una serie de constantes sobre las que vamos a profundizar. Los elementos que se repiten, y que en definitiva nos han servido para definirlos, pueden establecerse en dos niveles independientes pero relacionados entre sí: paleoecológicos y arqueológicos.

Siempre son sitios al aire libre y emplazados en medios sedimentarios sometidos a una dinámica de baja o nula energía, en llanuras de inundación de ríos, generalmente con un largo estiaje, o de pantanos y charcas de aguas someras de carácter palustre y/o lacustre. Este hecho puede responder muy bien a un sesgo tafonómico resultado de unas condiciones sedimentarias en medios que favorecen la preservación y perduración de los restos, en la mayor parte de los casos, en posición primaria. Si esto es así, la posibilidad de que yacimientos similares pero emplazados en medios diferentes se hayan preservado, parece muy escasa con la consiguiente pérdida de información. A su vez, la diversidad de factores que condicionan los procesos de sedimentación en medios de baja energía, obliga a dar una importancia primordial a la compresión de la dinámica del medio. Es preciso evaluar y analizar minuciosamente dichos factores y los procesos sedimentarios en estos medios, antes de establecer el alcance y significado de las similitudes y diferencias observadas. Así, es importante por ejemplo, conocer el ratio de sedimentación y la agresividad del medio (periodicidad de las crecidas e inundaciones de las llanuras aluviales o lacustres), que junto a elementos como la alzada, peso o morfología de los restos, va a incidir en el tiempo de enterramiento y en la dispersión de los mismos. Pensamos que cualquier intento de excavación de un yacimiento de este tipo debe partir de la necesidad de comprender la dinámica que ha permitido su preservación y contemplar todos aquellos elementos que nos sirvan para entender las relaciones entre los restos. Sólo así, seremos capaces de establecer qué tipo de información nos puedén ofrecer.

Es ahí, donde podemos establecer una segunda constante en estos yacimientos, ya que proporcionan fundamentalmente una información de tipo económico. Todos ellos han sido interpretados por sus excavadores como áreas de despedazado de un elefante para la adquisición de recursos, al menos, cárnicos.

Las constantes paleoecológicas y arqueológicas que examinaremos parecen evidenciar unas pautas de comportamiento, relacionadas con este tipo de actividad, sin que por ello seamos capaces de alcanzar, al menos de forma precisa, formas de conducta estereotipadas. Sobre esta cuestión volveremos a incidir en las consideraciones finales. Por otro lado, un análisis detallado de las características de los lugares de despedazado de elefante, permite establecer algunas diferencias dentro de las similitudes que proporcionan elementos de debate muy interesantes. A continuación abundaremos en esos elementos y en la información que nos aportan en puntos tan significativos como el momento de acceso por parte de un grupo humano a la carcasa de uno de estos proboscídeos, o si el aprovechamiento se produce en una situación de acceso primario o secundario con la existencia o no de competencia en la adquisición del recurso. En última instancia, pueden avanzarse hipótesis ligadas a la posible existencia de una variabilidad en la explotación de los cadáveres que incluye actuaciones más o menos oportunistas frente a actividades que denotan un cierto grado de previsión y planificación.

T. P., 55, n. ${ }^{\circ} 1,1998$ 


\section{Medio}

Ya hemos señalado que todos los yacimientos tipo 1 comparten su emplazamiento en medios sedimentarios de aguas someras y tranquilas, charcas de carácter palustre o lacustre (Barogali, Mwanganda, Lehringen) o llanuras de inundación de lagos y ríos (Olorgesailie, Venosa Notarchirico, Arriaga, Áridos). Aún así, habría que comenzar por intentar establecer si han existido diferencias importantes en cuestiones como el lapso de tiempotranscurrido entre la muerte del animal y el enterramiento completo de sus restos o la agresividad del medio.

El estado de conservación de los huesos, fundamentalmente costillas, con fracturas transversales debidas a un fenómeno de retracción de arcillas y una fuerte costra de carbonatos indicaba que en Barogali ese tiempo de exposición subáerea fue largo (Chavaillon et alii, 1987). De igual manera en Mwanganda el estado de conservación de los huesos estuvo determinado en gran parte por el proceso de sedimentación que sufrieron, con varios momentos de enterramiento y reexposición de los restos (Clark y Haynes, 1970). En estas condiciones parece lógico plantearse la posibilidad de aprovechamientos secundarios de aquellos restos que hubieran permanecido visibles, bien por grupos de homínidos, bien por carnívoros. Esa segunda actuación, de haberse producido habría afectado muy probablemente a la dispersión de los elementos óseos, o al menos parte de ellos, y en caso de estar protagonizada por homínidos implicaría, posiblemente, un nuevo aporte de industria lítica al sitio. Por este motivo, es importante establecer si este tipo de aprovechamiento secundario existió y si fue así que papel habría jugado en la formación del agregado arqueológico de cada yacimiento. En el caso de Arriaga, sus excavadores, en función de las características sedimentológicas del nivel y del mal estado de las superficies corticales de los huesos, consideran que el tiempo de enterramiento fue lento (Rus y Vega, 1984); no obstante, la escasa dispersión de los elementos anatómicos del elefante, prácticamente en conexión anatómica, podría ser indicativa de que no se dio un aprovechamiento intenso de la carca$s a$, ni actuaciones posteriores sobre aquellas partes que no hubieran sido aún enterradas.

La falta de marcas de mordisqueo sobre los huesos junto a la inexistencia de una diversidad taxonómica tanto en número de restos como en variedad de especies representadas en el conjunto arqueológico puede entenderse desde el punto de vista de que los aprovechamientos secundarios o sucesivas visitas a estos sitios no se dieron o no fueron en ningún caso repetitivas. La presencia en un yacimiento clasificado como de actividad de despedazado (tipo B, Isaac, 1984) de huesos pertenecientes a individuos de otras especies ha sido interpretada y relacionada con la creación en el paisaje de lugares referenciales por parte de los homínidos (tipo C). Ejemplo en este sentido es el sitio FLK N6 en Olduvai (Tanzania) (2). En Barogali, Lehringen o Áridos 2 la diversidad taxonómica es nula, mientras que en Mwanganda (un molar superior de jirafa; un molar, una escápula y fragmentos de colmillos de un hipopótamo), Olorgesailie y Áridos 1 (restos craneales de dos bóvidos) (3) es muy escasa.

En Áridos 1 y 2, yacimientos distantes entre sí apenas unos $200 \mathrm{~m}$ y que comparten emplazamiento en una llanura de inundación fluvio/lacustre, resulta posible establecer diferencias en la agresividad del medio. En Áridos 2 el proceso de sedimentación resultó algo más violento, lo que incidió aunque de forma poco significativa en el desplazamiento de algunos restos, fundamentalmente líticos, por el empuje del agua (Santonja $e t$ alii, 1980).

La importancia del contexto sedimentario en la formación y preservación del agregado arqueológico se comprueba con claridad en Venosa Notarchirico, donde el proceso de sedimentación, en un nivel de arenas y gravas, es complejo, con unos restos localizados en el interior de ese sedimento y otros sobre el mismo, en su base o incluso en contacto con niveles superiores (Lefévre et alii, 1994). Todo ello dificulta la compresión de la posición estratigráfica de la industria lítica, de los elementos óseos, y en definitiva, de su relación estricta o no.

\section{Patrón de Explotación}

En Barogali se identificaron tres agrupaciones principales de restos óseos en función de su dis-

(2) Bunn y Potts (Bunn, 1982) ya señalaron que este sitio no era representativo de un lugar de despedazado tomando como definición la establecida por Isaac $(1978 ; 1984)$ para butchering site y living floor.

(3) Con ciertas dudas acerca de su pertenencia a la misma paleosuperficie al no haberse hallado más restos de estos individuos y no contar con criterios determinantes (Santonja, comunicación personal). 
persión sobre la superficie y de la mayor concentración de material lítico (cráneo, parte superior del cráneo, esqueleto postcraneal). Si bien la superficie excavada fue de unos $35 \mathrm{~m}^{2}$, los restos del elefante aparecían dispersos en $30 \mathrm{~m}^{2}$. Destaca una muy escasa presencia de huesos largos con claro predominio del esqueleto axial (Chavaillon et alii, 1987). Los excavadores señalaron, a su vez, la existencia de una serie de fracturas longitudinales sobre los huesos largos, muy raros en el sitio, a las que atribuyen un posible origen antrópico. Estas marcas de corte se habrían realizado poco tiempo después de la muerte del elefante como consecuencia de una manipulación de los restos por parte de los homínidos (Chavaillon et alii, 1987). La industria registrada en el sitio (550 piezas) mostraba un claro predominio de lascas (más de 400) y de la búsqueda de filos de corte (Berthelet et alii, 1992). También se establecía que la talla y producción de lascas se había realizado en el lugar. Por último, se afirmó que los homínidos habían tenido un acceso temprano a los restos y en situación no competitiva.

Tres fueron también las agrupaciones principales identificadas en Mwanganda partiendo de la dispersión de los restos líticos y óseos (en torno a las costillas, al fémur y debajo de éste). En esta ocasión los restos cubrían una superficie de unos $80 \mathrm{~m}^{2}$. Entre los elementos anatómicos registrados destaca la mayor presencia del esqueleto axial (Clark y Haynes, 1970). La serie industrial (314 piezas) se compone esencialmente de productos de talla $(77 \%)$ con un porcentaje muy similar en útiles y piezas utilizadas (12\% y 11\%) (Clark y Haynes, 1970). A partir del estudio comparado de las lascas y núcleos encontrados en el sitio, los excavadores llegaron a la conclusión de que los nódulos que se adecuaban a tal producción de lascas debieron de ser aportados desde el exterior del yacimiento, teniendo lugar, posteriormente, el proceso de talla en el mismo sitio. Además, la presencia de dos lascas de avivado de bifaz estaría indicando el empleo de este tipo de utensilios y su reutilización o reelaboración en el sitio y en definitiva el aporte premeditado de materia prima ya formatizada al lugar.

En Olorgesalie 15, los excavadores señalaron una similitud muy alta en la dispersión de restos líticos y óseos sobre una superficie de $23 \mathrm{~m}^{2}$. Los homínidos habrían tenido acceso a los restos en situación primaria y no competitiva al no observarse marcas de mordisqueo sobre los huesos del elefante, y ello, pese a encontrarse emplazado el sitio en la margen distal de la playa de un lago, con escasa protección arbórea y sujeto por tanto a una presión trófica alta (Potts, 1989) (4). La industria registrada, en torno a las 350 piezas líticas, está dominada por lascas con filo agudo. En opinión de los excavadores los bifaces, ausentes en el sitio (aunque abundantes en los lugares próximos a los cursos de agua cercanos al paleolago), habrían estado presentes en el sitio cuando se despedazó el elefante, funcionando como expendedores de cuchillos, que no fueron abandonados con posterioridad en el lugar (Potts, 1989). Una vez más, estaríamos, muy probablemente, ante el aporte premeditado de matera prima ya formatizada al yacimiento.

En Áridos 1 la extensión excavada fue de 112 $\mathrm{m}^{2}$, encontrándose los restos del elefante en la paleosuperficie más antigua de las dos identificadas, dispersos sobre una superficie de unos $40 \mathrm{~m}^{2}$ (Santonja y Querol 1980c: 325). Se diferenciaron tres agrupaciones de restos (en torno al cráneo, junto al hueso de la pelvis y a 4 o 5 metros a la derecha del cráneo). Los elementos anatómicos hallados pertenecen al esqueleto axial (Soto, 1980: 213), evidenciando la falta de marcas de mordisqueo un acceso temprano de los homínidos a los restos del elefante y en situación no competitiva. La serie industrial es amplia, 331 piezas, con una dispersión similar y cerrada a la de los huesos del animal, en esta ocasión sobre unos $30 / 40 \mathrm{~m}^{2}$. Predominan las esquirlas y fragmentos $(71 \%)$, mientras que los utensilios (4\%) realizados la mayoría con retoques sumarios no han sido muy elaborados (Santonja y Querol, 1980a: 265), encontrándose 13 lascas levallois con microrretoques, 6 escotaduras, 3 denticulados, 3 cuchillos de dorso, 2 buriles diedros y 5 planos, $1 \mathrm{bec}, 1$ raspador nucleiforme y 1 raedera sobre cara plana junto a 4 cantos tallados. En el conjunto de piezas destaca una vez más, el predominio de los filos de corte (Villa, 1990). Se registraron dos lascas de avivado de bifaz que evidencian su empleo en las actividades desarrolladas en el sitio. El aporte premeditado de materia prima al yacimiento, en parte ya for-

(4) Situado a unos dos kilómetros de la margen del paleolago, el sitio se encontraría prácticamente en el límite entre el bosque aluvial de la orilla del lago y la sabana herbácea. En esta zona de transición la presión trófica habría sido mayor y por está razón algunos investigadores piensan que las actividades de despedazado fueron breves y dirigidas a obtener las partes más provechosas, que serían trasladadas para su consumo a lugares preferenciales más seguros (Domínguez Rodrigo, 1994: 200).

T. P., 55, n. $^{\circ} 1,1998$ 
matizada (bifaces), habría consistido fundamentalmente en el transporte de nódulos, muy probablemente, recogidos en la misma llanura aluvial.

En Venosa Notarchirico los restos aparecen dispersos sobre una paleosuperficie de gravas en un área de $24 \mathrm{~m}^{2}$ (Lefèvre et alii, 1994). El proceso de formación del sitio tal y como ya hemos señalado con anterioridad no ha permitido contrastar de modo definitivo la relación estricta entre los restos del elefante (tan sólo el cráneo y las dos defensas) y gran parte del material lítico. Los argumentos en favor de una hipótesis de despedazado se reducen, prácticamente, a la dispersión topográfica de los restos líticos (42 piezas), o al menos una parte de los mismos, concentrados en torno a los restos craneales. Además, la posición desplazada de la mandíbula en relación al cráneo y la postura invertida del mismo (Guidi y Piperno, 1992: 168169) podría evidenciar una manipulación y separación deliberada de ambos por parte de un grupo humano. En la serie industrial dominan bifaces, choppers y en menor medida instrumentos sobre lasca (Guidi y Piperno, 1992). Con todo, no se puede afirmar de forma categórica que la distribución de los restos responda a la realización en el lugar de actividades relacionadas con el despedazado de un elefante (Guidi y Piperno, 1992: 169).

Desconocemos la extensión de la superficie que cubrían los restos hallados en Lehringen (Thieme et alii, 1985) pero a tenor de otros datos como la práctica conexión anatómica de todos los elementos del esqueleto, podemos pensar que fue menor que la vista en los sitios mencionados arriba. También es menor el número de piezas que componen la serie industrial, una treintena, en su mayor parte lascas no modificadas (5), junto a lo que se ha interpretado como una lanza de madera (Movius, 1950; Tode, 1954). El elefante apareció prácticamente completo y como ya hemos señalado en conexión anatómica (Movius, 1950). Se ha interpretado que los homínidos tuvieron un acceso restringido a ciertas partes, prácticamente la trompa y la parte superior de la cabeza, debido muy probablemente a que el resto del animal permaneció hundido en el fango (Müller-Beck, 1982). Un paralelo interesante, también en Alemania, es el yacimiento de Gröbern aunque con una cronología más reciente. En el verano de 1987

(5) Sin embargo, para Müller-Beck (1982: 331) estas lascas están producidas claramente mediante el empleo de método levallois. fueron hallados en este sitio los restos de un individuo joven de Palaeoloxodon antiquus junto con piezas líticas. El esqueleto aparece muy completo con elementos en conexión anatómica y escasa dispersión (Weber y Litt, 1991).

En Arriaga II la superficie excavada alcanzó los $56 \mathrm{~m}^{2}$, aunque la extensión atribuida a la asociación entre los restos líticos y óseos se limitó finalmente a $35 \mathrm{~m}^{2}$. Destaca, al igual que en Lehringen, el alto grado de conexión anatómica de los restos del elefante que se agrupaban en 7 u $8 \mathrm{~m}^{2}$ (Rus y Vega, 1984). Es claro el predominio del esqueleto axial, hallándose los diferentes elementos prácticamente en conexión anatómica, aunque en posición algo forzada con las costillas y vértebras desplazadas, resultado, posiblemente, de una manipulación postmortem del individuo (Rus y Vega, 1984: 400). Para sus excavadores resulta evidente la acción de despedazado y aprovisionamiento, al menos de carne, ya que sólo quedaron en el sitio los restos con menor contenido cárnico, aunque falta la pelvis, señalándose la presencia de un hueso fracturado por causas que no pueden considerarse naturales (Rus y Vega, 1984). La postura del elefante es indicativa como ya hemos comentado de una posible manipulación por parte de los homínidos (costillas dispersas y vértebras descolocadas). La serie industrial asociada en relación estricta al elefante también es escasa, 43 piezas, con predomino de los filos cortantes. Aún así, aparecen núcleos, bifaces, lascas y fragmentos, en ocasiones ligeramente modificados por retoques de reavivados para su reutilización, por lo que también se habrían realizado tareas de talla en el sitio. Se empleó la materia prima del entorno más inmediato al lugar (Rus y Enamorado, 1991: 271) por lo que interpretamos que ésta se recogió en el momento de realizar la actividad que asocia la industria hallada al elefante y que por tanto, no es tan evidente el aporte premeditado de la misma, señalado en otros lugares.

Los restos hallados en Áridos 2 pertenecían a un individuo que apareció tumbado sobre su lado derecho. Los huesos se corresponden con el esqueleto axial prácticamente en conexión anatómica y en relación estricta con 28 piezas líticas sobre una superficie de $12 \mathrm{~m}^{2}$. La pala excavadora que dejó al descubierto el elefante habría arrancado la práctica totalidad de los huesos del lado izquierdo, principalmente las costillas (Santonja et alii, 1980). Con todo, parte de esos huesos del lado izquierdo pudieron haber sido aprovechados por los 
homínidos. La disposición de la columna vertebral evidencia que el animal sufrió una muerte lenta (Soto, 1980: 221). Los excavadores señalan que la posición del esqueleto y el desprendimiento del cráneo habrían estado condicionados muy probablemente por la intervención humana. En la serie industrial dominan las lascas, aunque aparecen un hendedor y un bifaz (Santonja y Querol, 1980b: 300).

La similitud entre las agrupaciones de restos óseos y líticos registradas en estos sitios, así como la dispersión y posición de los elementos anatómicos, evidencian una manipulación por parte de los homínidos de carcasas de elefante. Por otra parte, la inexistencia de marcas de mordisqueo, la presencia básicamente del esqueleto axial o el predominio de filos cortantes en las industrias son indicativos de que el acceso fue temprano, en situación no competitiva con otros carnívoros y que cuando éste tuvo lugar los restos se encontrarían, muy probablemente, en buenas condiciones. No obstante, puede establecerse una diferencia en la intensidad de la explotación de los restos según los sitios. Esta conclusión se basa fundamentalmente en el grado de desconexión de los restos y en el posible aporte premeditado de materia prima ya formatizada (en nódulos o bifaces) al sitio (Villa, 1990). Yacimientos como Barogali, Mwanganda, Olorgesailie o Áridos 1 presentan en un principio una mayor extensión en la dispersión de los huesos de elefante (6), que sitios como Lheringen, Arriaga y Áridos 2 caracterizados por la práctica conexión anatómica de los huesos recuperados. En los primeros es más fácil diferenciar agrupaciones interpretadas como áreas de actividades autónomas aunque relacionadas entre sí, sugiriendo una aprovechamiento intenso de la carcasa. El mencionado aporte premeditado de materia prima a estos yacimientos en nódulos o en parte ya formatizada (bifaces) sugiere cierto grado

(6) En estos sitios siempre resulta problemático comprender cual es el grado de representatividad de la superficie excavada frente a la que pudo tener el yacimiento en su momento. Por ello, resulta arriesgado aventurar cual pudo ser la extensión original de los suelos de ocupación interpretados en una excavación, siendo en la mayor parte de las ocasiones imposible de contrastar las hipótesis que llevan a pensar que dichas áreas fueron más amplias. Ejemplos en este sentido son Arriaga II (Rus y Vega, 1984: 398), o Áridos 1 (Santonja, comunicación personal) y Áridos 2 (Santonja y Querol, 1980c: 325). Por otra parte, en sitios actuales donde se ha documentado una actividad de despedazado de elefante, la dispersión de los huesos puede alcanzar en ocasiones entre 200 y $700 \mathrm{~m}^{2}$ o aparecer en agrupaciones de 15 a $42 \mathrm{~m}^{2}$, separadas entre sí una veintena de metros, por citar algunos ejemplos (Crader, 1983: 118). de previsión o de planificación en las actividades desarrolladas, indicando que, al menos, los restos habrían sido avistados con anterioridad. La presencia de otros taxones, aunque escasa, podría ser resultado de posteriores visitas para reaprovechamiento de parte de los restos. Por contra, el escaso grado de desconexión anatómica estaría evidenciando una explotación poco intensa. Además, en estos casos, el número de piezas y su elaboración, generalmente, es mucho menor y la diversidad taxonómica nula, pareciendo responder a una ocupación mucho más breve y, quizás más oportunista, con una explotación menos intensa del elefante (pocos utensilios y escaso despedazado y dispersión de la carcasa), resultando mucho más difícil encontrar elementos para calcular el tamaño del grupo que participó en esa actividad.

En definitiva, podemos concluir que en los yacimientos tipo 1 puede plantearse la posibilidad de una intervención humana más o menos sistemática, pero evidente, sobre los restos de un elefante. Estaríamos en presencia de acciones elementales y procesos singulares relacionados con el despiece de un proboscídeo y la adquisición de al menos carne. También pueden identificarse en este tipo de yacimientos gestos técnicos relativos a la talla de material lítico. Son siempre el resultado de una actividad limitada, desarrollada en un margen de tiempo breve y por grupos reducidos.

\section{Yacimientos tipo 2}

Sus características son bien diferentes de las que acabamos de establecer para los yacimientos tipo 1 y son el resultado de unos procesos de formación diferentes tanto por la naturaleza de la intervención humana que pudiera haberse dado como, fundamentalmente, unas historias tafonómicas mucho más complejas que han afectado desde un principio al número, dispersión y relaciones entre los restos preservados. En estos lugares el impacto humano es difícil de determinar y de caracterizar, aunque el hallazgo de industria demuestra al menos una presencia y apunta a que el agregado arqueológico es fruto de un impacto débil y esporádico. Elementos como la mayor extensión, número y diversidad de taxones representados o las características de las industrias (integridad de la cadena operativa, grado de homogeneidad en tecnológica, tipología o estado de conservación), llevan a pensar que estamos ante

T. P., 55, n. $^{\circ} 1,1998$ 
lugares donde el agregado faunístico y arqueológico no siempre está relacionado de forma estricta, $o$ en todo caso se debe a la sucesión en el tiempo de episodios esporádicos y más bien de carácter oportunista que producto de acciones sistemáticas.

Pese a ello, han dado lugar a toda una serie de interpretaciones basadas en cacerías y matanzas de elefantes por grupos del Pleistoceno medio, que hoy por hoy, deben descartarse por su falta de solidez y apoyo en el registro arqueológico recuperado (7). En la actualidad, la revisión crítica de estos sitios, unido en ocasiones a reexcavaciones (Ambrona y Torralba), o los hallazgos de lugares similares excavados ahora con nuevos planteamientos (La Polledrara di Cecanibbio), viene a demostrar que la naturaleza de la intervención humana es difícil de determinar y caracterizar especialmente si no se dispone de una información planimétrica y estratigráfica general y exhaustiva. Valiéndonos de la revisión que hemos realizado comprobaremos como la dinámica del medio y el proceso de formación juegan un papel fundamental para comprender las relaciones existentes entre el agregado faunístico y arqueológico y como en su configuración final pueden haber intervenido toda una variedad de situaciones naturales y antrópicas.

En Kärlich-Seeufer han quedado expuestos unos $400 \mathrm{~m}^{2}$ de una pequeña península formada en el extremo distal de un paleolago por sedimentos de arenas y gravas que procedían de derrubios de laderas adyacentes, sobre los que posteriormente se depositaron restos óseos y líticos (Kröger et alii, 1988). Entre los huesos recuperados se iden-

(7) Torralba es en este sentido un ejemplo de como una interpretación de este tipo se ha mantenido en la bibliografía internacional pese a que posteriores excavaciones y planteamientos han puesto en evidencia la falta de argumentos consistentes para admitir actividades de caza en estos lugares. Esta hipótesis ya lanzada por su primer excavador, el Marqués de Cerralbo (1915), y popularizada en la comunidad científica por Howell (1962) en los años sesenta, es la reflejada todavía por algunos investigadores en el último congreso internacional de ciencias prehistóricas y protohistóricas celebrado en Forli (Italia) en el mes de septiembre de 1996; "Les Oldowayens avaient-ils des moyens techniques et une organisation sociale suffisante pour effectuer des chasses-poursuite ou des chasse-piège. A Torralba, F. C. Howell évoque une telle chasse où les Acheuléens repoussaient l'éléphant dans un marécage. (...) D'autres sites de boucherie on servi de lieux d'abbatage ou de découpe pour un ou plusiers animaux. Par exemple (...) La Pineta à Isernia et Notarchirico, près de Venosa en Italie, Ambrona-Torralba en Espagne sont des gisements où les ossements d'animaux sont abondants, soit que l'animal ait été mangé sur place, soit que l'on ait transporté une partie de la carcasse dans un autre lieu plus apte à sa consumation". (Chavaillon, 1996: 81-82) tificaron un total de siete taxones, entre los que predominaba Palaeoloxodon antiquus con ocho individuos. La muestra de elefantes se componía esencialmente de elementos axiales, cráneos con molares y defensas, mientras que extremidades y parte posterior del esqueleto estaban poco representadas. Sobre la misma superficie se registraron unas 150 piezas líticas, fundamentalmente lascas poco retocadas, aunque estaban presentes también hendedores y bifaces. A la hora de interpretar la posible naturaleza de la intervención humana, los excavadores señalaron que la complejidad del proceso de formación del sitio con una dinámica del medio aún no bien conocida, quedaba limitada a señalar la presencia en el lugar de grupos humanos, puesto que la asociación topográfica sobre la misma superficie de restos líticos y óseos no era un criterio suficiente para establecer una relación estricta (Kroger et alii, 1988: 120). Aún así, el hallazgo de restos de frutos secos entre las piezas líticas y huesos podría apuntar en su opinión a la existencia en el sitio de actividades relacionadas con la alimentación de los homínidos. Quedaría pues por determinar cuál es el papel de los homínidos en los diversos procesos que intervinieron en la formación de este yacimiento (Gaudkzinski, 1996).

Entre 1980 y 1991 se excavaron cerca de 1100 $\mathrm{m}^{2}$ de una paleosuperficie con restos de elefante e industria lítica junto a otros taxones en Castel di Guido. Los excavadores piensan que el proceso de formación estuvo condicionado por un medio fluvio/lacustre, con zonas encharcadas y cursos de agua efímera de lechos poco profundos y muy amplios, como sobre el que se formó la paleosuperficie por ellos excavada (Radmilli y Boschian, 1996: 35). Pese a que conceden escasa agresividad a la energía de la corriente de agua de estos cursos, sí admiten que pudo haber un mínimo desplazamiento de los elementos óseos por la acción hidraúlica dando lugar a concentraciones en torno a los restos de mayor tamaño, peso y resistencia a la corriente. Esta afirmación nos lleva a pensar que por el mismo motivo una buena parte del material lítico podría encontrarse también en posición desplazada. Se recuperaron 5763 restos óseos pertenecientes a 11 taxones entre los que destacan: Bos primigenius (57 individuos), Equus caballus (23 individuos), Cervus elaphus (18 individuos) y $\mathrm{Pa}$ laeoloxodon antiquus (8 individuos). Los restos de elefante presentan una escasa conexión anatómica y dominan los elementos axiales, costillas, 
vértebras y en menor medida molares, defensas, cráneos y mandíbulas, siendo poco representativos los huesos de extremidades. En opinión de los excavadores ello es indicativo de que los elefantes se despedazaron en el sitio mientras que las muestras de caballo y bisonte parecen indicar que fueron cazados en otro lugar transportándose ciertas partes con posterioridad al sitio excavado (Radmilli y Boschian, 1996: 87). La serie industrial se compone de 1273 piezas líticas donde destacan lascas y útiles sobre lasca (raederas, denticulados y escotaduras) (26\%). Aparecen también choppers $(4 \%)$ y bifaces $(5 \%)$. Incluyen en la serie un amplio número de cantos que definen como $\mathrm{ma}$ nupports $(63 \%)$ que habrían sido utilizados para fracturar huesos y acceder al tuétano (Radmilli y Boschian, 1996). Así mismo, se indica la existencia de industria sobre hueso, lascas y lascas retocadas y bifaces que se relaciona con la escasez o dificultad de acceso a materia prima lítica apta para la talla (Guido y Piperno, 1992: 160). En nuestra opinión los argumentos para establecer una relación estricta entre restos óseos e industria son insuficientes y la energía del medio pudo haber jugado un papel importante en la formación del agregado arqueológico y faunístico.

Esto fue sin duda alguna lo que ocurrió en Rebbibia-Casal de ${ }^{\prime}$ Pazzi donde la acción de una corriente fluvial dio lugar a una importante concentración de restos óseos y líticos. La superficie excavada, unos $1200 \mathrm{~m}^{2}$, forma parte del lecho de un antiguo río excavado en una formación volcánica con depósito de arenas y gravas de origen piroclástico. El área excavada se encontraría en un meandro donde la fuerza de la corriente modeló una barrera natural en la que numerosos huesos de gran tamaño quedaron atrapados entre los bloques y rocas erosionados por el río (Anzidei y Rufo, 1985). Se contabilizaron unos 2000 restos óseos entre los que se identificaron 13 taxones. Los huesos de Palaeoloxodon antiquus se correspondían fundamentalmente con molares y defensas. Cráneos, mandíbulas, pelvis o fragmentos de costillas eran muy escasos. De las extremidades, tan sólo, se identificó un húmero. El estado de conservación de los huesos no era homogéneo. La serie industrial se componía de 1700 piezas líticas, destacando el grupo de las raederas sobre lasca, con baja frecuencia de denticulados, escotaduras o raspadores y escasa presencia de bifaces y choppers. Los excavadores interpretan que tanto restos líticos como óseos habrían sido redepositados por una corriente de agua desde lugares diferentes, posiblemente, en el tiempo y en el espacio (Anzidei y Rufo, 1985).

Más difícil de interpretar es el proceso de formación de las paleosuperficies excavadas en Isernia La Pineta y el papel de los grupos humanos en la concentración de restos óseos y líticos. Desde 1978 hasta 1994 se han excavado en superficie cerca de $300 \mathrm{~m}^{2}$ repartidos en cuatro paleosuperficies (8) (Peretto, 1996). Nuestra revisión se centró de manera fundamental en el sector I de la excavación y en el suelo de ocupación t.3a $\left(140 \mathrm{~m}^{2}\right)$ que contenía la concentración de restos más espectacular. Nos encontraríamos ante un yacimiento con una historia tafonómica muy compleja y ligada a la proximidad de un medio acuático fluvio/lacustre. Esta paleosuperficie se formó sobre un piso de lodo depositado por alguna corriente cercana y posteriormente enterrado por otro depósito fluvial, esta vez de alta energía (Peretto, 1991). Los restos se habrían depositado antes de la consolidación del piso de lodo. Se registraron 4240 restos óseos identificándose siete taxones; Bison schoetensacki (61individuos), Stephanorinus hundsheimensis (31 individuos), Ursus deningeri (12 individuos), Palaeoloxodon antiquus (8 individuos), Hippopotamus antiquus (2 individuos), Megaceroides solilhacus (2 individuos), Dama dama clactoniana (1 individuo) y Phantera leo fossilis (1 individuo). Los huesos de elefante son principalmente fragmentos de defensa, dientes aislados y en menor medida fragmentos también de escápulas, vértebras, húmeros o fémures. Destaca pues el hecho de que los huesos se encuentren muy fragmentados (Anconetani, 1996). En cuanto a la industria, el estudio más detallado se centra en los restos líticos registrados en una porción de $30 \mathrm{~m}^{2}$ de esta superficie. De 1685 restos, el $75 \%$ son bloques de travertinos, un $17 \%$ cantos de caliza y tan sólo un $8 \%$ son piezas de sílex. Finalmente la serie industrial se reduciría a 130 piezas ( 72 de caliza y 58 de sílex). Destacan los útiles sobre lasca y dentro de ellos los denticulados, contabilizándose un buen número de choppers y núcleos en su mayor parte de caliza. En opinión de los excavadores la mala calidad del sílex determinó en gran manera la configuración de la industria en cuestiones como el tamaño de la piezas o los retoques (Giusberti y

(8) Sector I de excavación: t.3c $\left(58 \mathrm{~m}^{2}\right)$, t.3a $\left(140 \mathrm{~m}^{2}\right), 3 \mathrm{~S} 10$ $\left(12 \mathrm{~m}^{2}\right)$. Sector II de excavación: t.3a $\left(72 \mathrm{~m}^{2}\right)$ (Peretto, 1996).

T. P., 55, n. ${ }^{\circ} 1,1998$ 
Peretto, 1991). La intervención de los homínidos sobre los restos de elefantes se habrían centrado fundamentalmente en la fractura intencionada de los huesos para acceder a la médula ósea y en menor medida en tareas de despedazado ya que las marcas de corte y desarticulación son muy escasas. En cuanto al patrón de adquisición de esas carcasas se mantiene que mientras los bisontes habrían sido posiblemente cazados, en el caso de los elefantes se habría optado por una estrategia oportunista de carroñeo de individuos muertos por causas naturales (Anconetani, 1996: 132).

El yacimiento de Torralba, al igual que el de Ambrona, es ejemplo de como han ido evolucionando las interpretaciones en torno a este tipo de sitios con importantes acumulaciones de elefantes, desde la imagen de los cazaderos de megafauna (Marqués de Cerralbo, 1915; Howell, 1962; Freeman, 1994), pasando por los escenarios de carroñeo marginal (Binford, 1981, 1987), a los planteamientos basados en un conocimiento exhaustivo de la dinámica del medio y de las relaciones entre restos que nos permitan evaluar el alcance del impacto humano o el papel de los mecanismos naturales (Villa, 1990; Santonja, 1989; Santonja y Villa, 1990). Entre 1961 y 1963 se excavaron aproximadamente $1026 \mathrm{~m}^{2}$ de una superfice con sedimentos de arenas y gravas que proporcionaron una gran cantidad de restos óseos. Se estableció la presencia de 12 taxones diferentes con discrepancias según los autores a la hora de establecer el número mínimo de individuos. Según Freeman (1994: 609)Aguirre contabilizó 2141 restos mientras que Klein (1987) tan sólo 1521, de manera que el primero estableció para Palaeoloxodon antiquus un número de 37 individuos y el segundo lo redujo a 14. La industria lítica recuperada en las excavaciones de esos años alcanzó la cifra de 887 piezas (Freeman, 1975: 668). Dominan la serie los utensilios sobre lasca (32\%), fundamentalmente raederas y denticulados, al igual que las lascas no retocadas $(25 \%)$ o ligeramente retocadas $(24 \%)$. Aparecen también bifaces y hendedores (8\%). Destaca la baja densidad de industria, poco representativa en relación a la fauna, como posible indicio de un débil impacto humano en el yacimiento. De igual manera, la relación entre bloques tallados y lascas en torno a 1:5 es de un valor excesivamente alejado de los obtenidos en sitios claramente en posición primaria como Áridos 1:24; y más cercano a los registrados en ambientes plenamente fluviales e indicativos de un déficit importante en productos de talla, muy probablemente achacables a un transporte fluvial o a una excavación inadecuada que no permitió recoger todos los materiales. La existencia de núcleos y lascas de talla podría sin embargo demostrar que se talló en el lugar, con independencia de que la materia pudiera o no haber sido introducida en diferentes estados de elaboración. La introducción de piezas ya formatizadas o en proceso de elaboración podría implicar un cierto grado de previsión, mientras que los múltiples procesos de retoque observados en los utensilios sobre lasca o en los hendedores parecen indicar lo contrario. Las representaciones de los diferentes elementos anatómicos en la fauna estarían de alguna manera también condicionados por el posible transporte fluvial, así como por el tiempo de exposición subaérea, factor claramente relacionado con la dinámica de los depósitos (Santonja, comunicación personal). Sobre las posibles evidencias de intervención humana que los huesos pudiesen presentar, hay que señalar que, pese al mal estado de conservación de las superficies de los mismos, se comprobó la existencia de microhuellas de cortes en algunos casos sobre huesos de elefante (Shipman y Rose, 1983: 467-468). Interesa destacar aquí, las interpretaciones realizadas en torno a las cuatro "ocupaciones" que fueron identificadas en un nivel de gravas denominado B4a (Freeman y Butzer, 1966). En una de éstas, de unos $50 \mathrm{~m}^{2}$, aparecían los restos de un elefante, no en posición anatómica, pero sí escasamente dispersos. La mayor parte de los huesos pertenecían a la mitad izquierda. Junto a ellos se registró la presencia de 6 piezas líticas (tres de ellas núcleos). Se interpretó el área como un lugar de despedazado inicial de este animal, habiéndose realizado en las otras áreas tareas secundarias vinculadas con ese despedazamiento y dirigidas fundamentalmente al consumo de carne (Freeman y Buzter, 1966: 17). Como han señalado algunos autores, para juzgar la consistencia de tales interpretaciones y conocer el grado de integridad y significación de las "ocupaciones" es fundamental tratar de determinar el papel de los procesos sedimentarios en la "ubicación de las piezas y en la formación de agregados y discontinuidades", para lo cual se necesitarían planimetrías detalladas, además de datos precisos sobre la posición estratigráfica real de los restos (Santonja et alii, 1997: 55). De este modo, los problemas que plantea Torralba están relacionados, en un primer lugar, con la necesidad de demostrar que la dinámica sedimentaria permitió mantener las rela- 
ciones entre los restos y a partir de ahí tratar de desarrollar unos criterios de excavación que permitan reconocer tales relaciones o reinterpretar datos anteriores, planteamientos que han motivado las excavaciones reemprendidas en Torralba yAmbrona desde 1993.

Mientras que desde los trabajos de Howell se consideró que Torralba y Ambrona eran yacimientos gemelos y por tanto insertos en la misma formación geológica (Butzer, 1965), las investigaciones más recientes han ligado morfológicamente al primero con la evolución de un valle con terrazas escalonadas y al segundo con la de un poljé (Pérez González et alii, 1991, 1997). Hasta el momento de reemprender las actuales excavaciones, la extensión de la superficie excavada en diferentes campañas (1914-1916, 1962-1963, 1973, 1980-1981, 1983) es de unos $2717 \mathrm{~m}^{2}$. Según Howell (Howell et alii, 1995) los restos óseos registrados en el denominado Complejo inferior han permitido identificar 41 taxones, con una nueva discrepancia en el número mínimo de elefantes considerados por Aguirre y Klein, 47 y 16 respectivamente. La industria de este complejo alcanza prácticamente unas 1300 piezas líticas, con claro dominio de lascas. Las cadenas operativas se encuentran muy fragmentadas (Panera, 1996) pudiendo relacionarse este hecho con una acción tractiva del medio. De nuevo el principal problema para establecer líneas de interpretación pasa por la comprensión de la dinámica del medio. Ambrona parece haber sido un lugar relacionado con los márgenes de una gran charca. Los restos de fauna e industria atribuidos al Complejo inferior se acumulan preferentemente en los niveles inferiores que corresponden a medios lacustres de energía nula o muy baja por lo que presentan las condiciones necesarias para permitir la conservación de materiales en posición primaria. Sin embargo, se desconoce su ritmo de funcionamiento sin que tampoco se hayan identificado paleosuperficies en estos niveles, debido quizás a que en este tipo de medios no se hubieran construido en condiciones de ser reconocidas. Es imprescindible tratar de evaluar el tiempo a través del cual se acumularon los restos registrados en estos niveles para intentar reconocer en términos de sincronía estricta las relaciones entre los mismos. La presencia humana en el yacimiento parece ser esporádica y reducida, con un débil impacto en la formación del agregado arqueológico y faunístico (Santonja et alii, 1997: 63). Así parece evi- denciarlo, entre otros factores, la baja densidad de piezas líticas, la falta de homogeneidad de algunos tipos de utensilios, como los bifaces, y la variedad de materias primas alóctonas al yacimiento o unas cadenas de talla incompletas (Santonja et alii, 1997: 58). Se han detectado marcas de corte sobre algunos huesos (Shipman y Rose, 1983; Freeman, 1994), aunque hay que indicar que se examinaron muestras parciales y que muchos restos presentan sus superficies externas muy alteradas, con lo que la información obtenida no es muy significativa. Resulta muy difícil integrar en un sólo mapa de dispersión de restos las diferentes superficies excavadas en sucesivas campañas por lo que es prácticamente imposible considerar áreas significativas.

Las excavaciones realizadas por el actual equipo de investigación en los años 1993, 1995 y 1996 han dejado al descubierto una extensión de unos $257 \mathrm{~m}^{2}$ del Complejo inferior. Una aproximación estratigráfica inicial ha llevado a distinguir cinco niveles con industria y fauna. Los restos de elefante son especialmente abundantes en un nivel de margas de origen lacustre de escasa potencia (AS3). Cabe destacar que la distribución de la fauna sobre la superficie no es homogénea, registrándose amplios espacios "desprovistos de restos hasta una zona de alta concentración". En esta zona, de unos $50 \mathrm{~m}^{2}$, fue hallado el esqueleto prácticamente completo de un elefante macho adulto-senil y escasos huesos que no pertenecían a ese individuo. Por el momento no se han encontrado evidencias (marcas de corte o industria lítica relacionable...) sobre una posible actividad o presencia humana relacionada con estos restos (Santonja et alii, 1997: 63).

La complejidad del yacimiento podría reflejarse en la existencia de varias superficies y dispersiones de restos, aún en la misma unidad sedimentaria, con agrupaciones de fauna y/o industria lítica sujetas a diferentes matices, independientes en el tiempo y en el espacio, que puedan responder a diversas interpretaciones.

Una situación de este tipo es la que parece evidenciarse en el yacimiento de La Polledrara di Cecanibbio. Descubierto en 1984, las cinco campañas realizadas entre 1986 y 1993 han dejado expuesta una superficie de más de $500 \mathrm{~m}^{2}$. Los trabajos destinados a una comprensión de la dinámica del medio habrían sido determinantes a la hora de interpretar las agrupaciones de fauna y las relaciones entre restos líticos y óseos. En el proceso de

T. P., 55, n. $^{\circ} 1,1998$ 
formación del agregado arqueológico pueden diferenciarse dos fases claramente distintas. En primer lugar un contexto sedimentario fluvial, los restos aparecen dispersos en el lecho de un paleocanal, caracterizado por el transporte hidraúlico de huesos, principalmente de elefante y bisonte. La corriente de agua habría desplazado y depositado posteriormente los elementos líticos y óseos de forma que en la parte central del paleocanal éstos se agrupan en varios niveles y en las márgenes aparecen mucho más dispersos y en un sólo nivel. En estos márgenes el buen estado de conservación de los huesos estaría indicando un breve lapso de tiempo entre deposición y enterramiento (Anzidei et alii, 1989: 764). En esta zona, a su vez, la fuerza de la corriente habría sido menor por lo que no se produjo un desplazamiento de restos grandes, aunque sí de los más pequeños y de parte de la industria. Se recuperaron más de 7000 restos óseos, atribuibles al menos a ocho taxones: Bos primigenius, Palaeoloxodon antiquus y en mucho menor porcentaje Cervus elaphus, Dama dama o Equus caballus entre otros. El número mínimo de elefantes se situaría entre los diez individuos, dominando la muestra defensas, cráneos y mandíbulas con molares en posición anatómica. También aparecen pelvis, costillas, vértebras y extremidades, aunque en este último caso pocos elementos aparecen intactos. En ocasiones, los restos se encuentran en conexión anatómica: piezas de la columna vertebral, pelvis con fémur o huesos de extremidades anteriores y posteriores. La industria lítica, pues también se encontró en hueso, se compone de unas 350 piezas. La mayor parte de los útiles identificados fueron realizados sobre lasca: raederas, denticulados, escotaduras o raspadores, destacando el alto número de útiles múltiples o con más de un filo retocado. Entre los realizados sobre canto encontramos choppers y chopping tools. Parece que se habría dado una explotación intensa de la materia prima como consecuencia de la dificultad de obtención o acceso a la misma, hecho que justificaría también la presencia de industria en hueso de elefante o el posible reaprovechamiento de los restos líticos que pudieran haber sido abandonados en el sitio por visitas anteriores de grupos humanos (Anzidei et alii, 1989: 764).

Al mismo tiempo o inmediatamente después de esta fase fluvial, sigue un episodio de baja energía condicionado por un medio pantanoso que se habría desarrollado en las áreas periféricas de la superficie excavada. Los trabajos realizados entre
1993 y 1995 se han centrado en este área recuperando los restos de al menos dos elefantes adultos y un cráneo y mandíbula de Canis lupus. Los restos de elefante se encontraban parcialmente articulados y en muy buen estado de conservación. Los animales, probablemente, quedaron atrapados en el fango de las charcas, muriendo en el sitio y siendo rápidamente enterrados. La dispersión y acumulación de huesos, en estas zonas marginales, podría haber sido originada por la acción de predadores carroñeros (9) y/o por grupos humanos (Anzidei et alii, 1989: 764). La actividad de estos últimos está documentada en las fracturas intencionadas de algunos elementos óseos y la presencia de industria lítica y ósea. Si bien es difícil determinar que grado de relación existe entre restos líticos y óseos, en todo caso el impacto humano habría sido débil y esporádico, y en ningún caso sistemático, sobre individuos muertos por causas naturales.

En La Cotte de Saint-Brelade, en la isla de Jersey, se excavaron dos niveles interpretados como episodios aislados de caza y despedazado de varios mamuts y rinocerontes lanudos (Callow y Conford, 1986). En ambos niveles, 3 y 6, los únicos mamíferos representados son Mammuthus primigenius y Coelodonta antiquitatis. Algunas de las características que vamos a reseñar acercan claramente este sitio a las interpretaciones relacionadas con los tipo 1, la diversidad taxonómica es prácticamente nula y la dispersión de restos cubre superficies menores a las hasta ahora vistas en los tipo 2 , si bien concentran un alto número de mamuts, 7 y 11, respectivamente. El enterramiento de los restos por loess habría sido rápido impidiendo alteraciones posteriores, aunque pudo haber algún sesgo tafonómico por la preservación diferencial de los elementos óseos (Scott, 1980: 150). En el nivel 3 predominan entre los restos identificables de mamut, cráneos y mandíbulas, mientras que defensas y escápulas son más escasas. También aparecen algunas vértebras y fragmentos de costilla, mientras que únicamente hay un resto de hueso de extremidad. Por contra en el nivel 6 tan sólo hay restos de dos cráneos y dientes aislados, pese a que al menos ocho individuos estarían representados por elementos del esqueleto

(9) "Dans cette même zone on été partiellement dégagés, entre les côtes d'un éléphant, les restes d'un exemplaire de Canis lupus dont le crâne avec la mandibule et les os de l'extrémité d'un membre postérieur étaient encore en conexion anatomique." (Anzidei et alii, 1989: 763) 
postcraneal, escápulas, húmeros y fémures. Las costillas o fragmentos de éstas son escasas y no hay vértebras. Los perfiles de edad parecen similares, aunque mejor establecidos en el nivel 3, con predominio de animales adultos y algunas crías que no están presentes en el nivel 6. A la hora de establecer interpretaciones sobre la formación del agregado faunístico, para los excavadores la diferencia porcentual de elementos anatómicos representados en los dos niveles es importante. Desde un principio descartan que los animales hubiesen muerto en el sitio por causas naturales como extravíos o caídas en una trampa natural, ya que esto no explicaría las diferencias en elementos óseos representados. Tampoco atribuyen a predadores el transporte de estos huesos, demasiado grandes y pesados. Concluyen que la dispersión es fruto de la intervención de un grupo humano sobre los restos, principalmente de mamut (Scott, 1980: 145). La existencia de alguna marca de corte y de fracturas en las regiones parietales de los cráneos de mamut y rinoceronte estarían evidenciando tareas de despedazado y posiblemente el consumo de la masa cerebral. La novedad en este caso se centra en el patrón de adquisición de esos recursos pues por primera vez puede establecerse la posibilidad de que se hubiesen dado dos episodios de caza. El sitio está localizado al pie de un promontorio de granito lo que lleva a interpretar que la existencia de una garganta con gran caída habría sido aprovechada por un grupo humano para despeñar a los animales empujándoles a huir en esa dirección (Scott, 1980: 146). Esta hipótesis es defendida por los excavadores en especial para el nivel 3 en función del porcentaje de elementos óseos presentes y perfil de edad obtenido (10). La escasez de restos del esqueleto postcraneal en este nivel evidencia según ellos que una vez concluida la caza existió un tratamiento diferente de los restos en

(10) Aducen que el perfil de edad del nivel 3, podría estar representando un grupo de hembras jóvenes con sus crías que se vieron sorprendidas y empujadas al acantilado; "It is difficult otherwise to explain the presence of so many skulls which although comparatively young, would have been heavy and of little value as food" (Scott, 1980: 150). El problema es que los perfiles de edad no siempre son fáciles de establecer y de interpretar, sujetos a muchas problemáticas, con resultados controvertidos sobre su lectura atricional o catastrófica (Haynes, 1985: 342). En matanzas controladas en parques naturales del África Oriental ha podido observarse que un ataque sobre una agrupación de machos provoca una dispersión de los individuos en todas direcciones, mientras que ante semejantes circunstancias los grupos familiares de hembras con sus crías se agrupan (Haynes, 1991: 179-181), lo que podría entenderse como un argumento en apoyo de la hipótesis de los excavadores. relación a los del nivel 6 donde encaja menos la hipótesis del despeñamiento y se interpreta un transporte al sitio de las partes con mayor contenido cárnico desde un lugar de matanza cercano. Las tareas de despedazado habrían sido breves como demuestra la práctica inexistencia de industria lítica, principalmente lascas sin modificar y de pequeño tamaño, quizás indicadoras de las tareas de reavivado o fabricación de útiles en el sitio para las actividades de despedazado (Scott, 1980: 150).

\section{CONSIDERACIONES FINALES}

Las diferencias que hemos observado entre yacimientos tipo 1 y 2 están ligadas a procesos de formación distintos y con problemáticas singulares que requieren de planteamientos previos y específicos a su excavación que valoren la formación del agregado arqueológico como único punto de partida para obtener respuestas y soluciones (Tab. 2 y 3). Para estimar la capacidad informativa de estos sitios es importante adoptar un sistema de registro que permita recoger información espacial y microestratigráfica de todos los restos para comprender su distribución sobre la superfice y el grado de relación existente entre los mismos.

La información que hemos manejado es esencialmente de tipo económico, centrada en la posible intervención de grupos humanos sobre los restos de elefantes hallados en asociación con industria lítica. La mayor complejidad tafonómica de los yacimientos tipo 2 impide en la mayor parte de los casos establecer interpretaciones mínimamente rigurosas acerca de la naturaleza de la actividad humana.

Podríamos afirmar que en los yacimientos tipo 1 la intervención se traduce en la explotación organizada de la carcasa de un elefante, evidenciando el agregado arqueológico y faunístico acciones sistemáticas y breves, relacionadas con su despedazado. Por contra, en los tipo 2 el impacto y papel de los grupos humanos en la formación de ese agregado, parece ser esporádico o débil, en ningún caso fruto de acciones sistemáticas, sino más bien de una sucesión en el tiempo de episodios esporádicos y oportunistas.

La revisión de los yacimientos tipo 1, permite a su vez, plantear la posibilidad de acciones sujetas a un cierto grado de previsión o planificación (introducción premeditada de materia prima ya formatizada al sitio o pautas de conducta en el despe- 
A) Posición primaria

- Llanura de inundación de un río.

- Las características litológicas y sedimentológicas evidencian un medio de baja energía.

- Buen estado de conservación de la industria con aristas y filos vivos que indican una falta de transporte fluvial de este material lítico.

- Remontaje de piezas in situ.

- Coherencia y homogeneidad de la serie industrial desde el punto de vista tecnológico.

- 7,2 piezas líticas y 1 útil por $\mathrm{m} 2$.

- Ratio nódulos / lascas de 1:24.

- Buen estado de conservación de los restos óseos y falta de orientaciones preferenciales en su dirección y disposición sobre la superficie excavada.

- Presencia de pequeñas esquirlas óseas.

\section{B) Relación estricta entre los restos}

- Tanto los restos del elefante como las 331 piezas líticas a él asociadas se encuentran en la misma superficie de escasa potencia.

- Las dispersiones de ambos tipos de restos son similares y bastante cerradas.

- Piezas líticas incrustadas en el cráneo y otros huesos del elefante.

C) Área de despedazado de un elefante con cierto grado de planificación y previsión

- Un único individuo (Palaeoloxodon antiquus) posiblemente una hembra subadulta.

- Escasa diversidad taxonómica.

- Predominio entre la serie industrial de los filos de corte.

- Aporte de materia lítica ya formatizada al yacimiento (bifaces).

- Piezas líticas incrustradas en el cráneo del elefante.

- Acceso a los restos temprano y en situación no competitiva deducida del grado de desconexión de los elementos anatómicos y de la inexistencia de marcas de carnívoros.

\section{D) Problemas}

- Representatividad de la superfice excavada versus la original del sitio.

Tab. 2. Áridos 1. Características y problemática de un yacimiento con restos de elefante Tipo 1.

A) Posición y relación de los restos

- Medio lacustre de energía nula o muy baja. Contexto sedimentario relacionado con los márgenes de una gran charca.

- Muy baja densidad de piezas líticas, entre 0,5 y 1 pieza por $\mathrm{m}^{2}$

- Ratio nódulos / lascas de 1:10.

- Posible desplazamiento vertical de materiales en la estratigrafía por acción de los elefantes.

- Falta de homogeneidad tipológica en algunos útiles (bifaces).

- Cadenas operativas muy fragmentadas.

- Variedad de materias primas alóctonas al yacimiento.

- Cerca de 40 individuos adultos con un mínimo de 12 hembras y, 8 o 9 individuos infantiles o subadultos, todos ellos reconocidos como Palaeoloxodon antiquus platyrhyncus.

- El predominido del esqueleto axial con ausencia de elementos anatómicos menos pesados sugiere la presencia de un agregado de carácter residual.

\section{B) Interpretación}

- Historia tafonómica compleja.

- Acciones esporádicas y débil impacto antrópico con imposibilidad de calcular su alcance justificadas por: la presencia de industria lítica y restos óseos en los mismos niveles; y existencia de marcas de corte en algunos huesos.

- Hipótesis alternativas centradas en mecanismos naturales.

- Agrupaciones diferenciadas sobre una misma superficie y/o posiblemente relacionadas que puedan responder a diferentes interpretaciones.

\section{C) Problemas}

- Discusión y conocimiento suficiente de la dinámica del medio.

- Control exhaustivo del grado de asociación existente entre los restos, de las relaciones espaciales, estratigráficas y microestratigráficas.

- Control topográfico preciso de la distribución y dispersión de los restos que permita distinguir asociaciones o unidades aisladas.

Tab. 3. Ambrona. Características y problemática de un yacimiento con restos de elefante Tipo 2.

dazado deducibles de la dispersión y desmembración de los elementos anatómicos) con significativas diferencias en la organización e intensidad de la explotación de las carcasas de elefante (Villa, 1990). Aún así, no debemos olvidar que esa capacidad de previsión estaría unida al desarrollo de 
una actividad muy concreta, el despedazado de un animal, que permite distinguir un cierto grado de planificación en la adquisición y explotación de un recurso. Los yacimientos tipo 2, con historias tafonómicas mucho más complejas, no permiten llegar a conclusiones de este tipo, si bien, algunas parecen apuntar a la existencia de varias superficies en un mismo yacimiento con agrupaciones diferenciadas y/o posiblemente relacionadas que puedan responder a diferentes interpretaciones (intervención humana sobre los restos, mecanismos naturales de acumulación de cadáveres (Haynes, 1988, 1991, etc.)

En relación al patrón de ađđquisición de este recurso, hemos apuntado que en los yacimientos tipo 1 parece observarse una planificación previa al desarrollo de una actividad sistemática como es el despedazado de un elefante, que permite en definitiva, contemplar alternativas que van desde un carroñeo primario a acciones más oportunistas o en último extremo un carroñeo marginal. En nuestra revisión hemos comprobado como los lugares equiparables a Ambrona o Torralba no proporcionan elementos ni argumentos de alta resolución que posibiliten realizar inferencias precisas sobre la naturaleza de la intervención humana cuando esta existió o acerca del patrón de adquisición del recurso. Aún así, no hemos hallado evidencias consistentes de actividades cinegéticas sobre elefantes (11). La excepción podría encontrarse en el

(11) Si bien en el yacimiento alemán de Lehringen, se halló una lanza de madera encajada entre las costillas de un elefante (Adam, 1951), pronto algunos investigadores destacaron que dicha lanza parecía estar más adaptada para una acción de empuje que de lanzamiento, puesto que el punto de equilibrio se situaba hacia el extremo inferior en lugar de colocarse cerca de la punta como cabría esperar para una mejor eficacia en el lanzamiento (Tode, 1954: 95). Otros autores recurrieron a paralelos etnográficos para justificar esta hipótesis; "Ituri Pygmy spears for thrusting into the under belly of an elephant are generally between $c$. 1.10 and $1.40 \mathrm{~m}$ long with a broad, leaf-shaped iron head (...), but longer ones (c. $2.10 \mathrm{~m}$ ) were sometimes used in Cameroon (...) This confirms that the Lehringen example, which otherwise might be considered overly long for the purpose, could also have been used for thrusting (...) Where dangerous game were involved, it is not surprising that long, heavy spears were sometimes preferred as, for example, the $4.0 \mathrm{~m}$ long, lion spears formerly used by Mbunda or (...) by the peoples of the "Nyasa Corridor" against elephant" (Oakley et alii, 1977: 23). Partiendo de estos argumentos parece aceptable, al menos, considerar que los homínidos hubiesen encontrado un elefante ya moribundo al que de alguna manera pudieron haber rematado (Movius, 1950: 142). No obstante, en Schöningen, un yacimiento datado en torno a los 400.000 años B.P., con restos de Palaeolox $\dot{\gamma}$ don antiquus, aunque interpretado como un cazadero de équidos y bóvidos, se ha descrito el hallazgo de útiles realizados en madera y entre ellos tres "lanzas" de unos $2 \mathrm{~m}$ de longitud que por su punto de equilibrio han sido definidas como jabalinas (Thieme et alii, 1993). yacimiento de La Cotte de Saint-Brelade, datado entre los 280.000 y 125.000 años BP., con el posible acoso y despeñamiento de un grupo de elefantes (Callow y Conford, 1986). De este modo cabría preguntarse si existió una variabilidad de comportamientos relacionados con la adquisición y explotación de ciertos recursos (megafauna) y en todo caso si esto puede comprobarse en el registro arqueológico desde un primer momento o responde a un proceso evolutivo de carácter más progresivo como podría estar anunciando el sitio de La Cotte de Saint-Brelade (Villa, 1990).

\section{BIBLIOGRAFÍA}

ADAM, K.D.(1951): "Der Waldelefant von Lehringen, eine, Jagdbeute des diluvialen Menschen". Quartär, 5:79-92.

AnConetati, P. (1996): "Lo studio archeozoologico del sito di Isernia La Pineta". En Carlo Peretto (ed.): I reperti paleontologici del giacimento paleolitico di Isernia La Pineta. Istituto Regionale per gli studi storici del Molise V. Cuoco. Italia: 87-186.

AnZIDEI, A.P. (1995): "La Polledrara, a middle Pleistocene site near Rome (Italy): Its bone and stone industry". En J. Gibert (ed.): Ocupaciones humanas durante el Pleistoceno Inferior en Oriente Medio, Java, Georgia y Europa. Resúmenes de las conferencias del Congreso Internacional de Paleontología Humana. Los homínidos y su entorno en el Pleistoceno Inferior y Medio de Europa. Septiembre, 1995. Orce (Granada): 100.

Anzidei, A.P.; Angelelli, F.; Arnoldus-Huyzendveld, A.; Caloi, L.; Palombo, M.R.; y Segre, A.G. (1989): "Le gisement pléistocene de 'La Polledrara' di Cecanibbio (Rome, Italie)". L'Anthropologie, 93: 749-782.

Anzidei, A.P.; Angelellli, F.; Caloi, L.; Damiani, I.; PaCCiarelli, M.; Palombo, M.R.; Saltini, A.C. y Segre, A.G. (1988): "Il giacimiento pleistocenico de 'La Polledrara' di Cecanibbio (Roma). Relacione Preliminare". Archeologia Laziale, IX: 361-368.

ANZideI, A.P. y Arnoldus-HuYzendveld, A. (1992): “The Lower Palaeolithic site of La Polledrara di Cecanibbio (Rome-Italy)". In E. Herring, R. Whitehouse and J. Wilkins (eds.): New developments in Italian Archaeology. Part 1, Papers of the Fourth conference of Italian Archaeology. Accordia Research Centre. London: 141-153.

AnZIDEI, A.P. y RufFo, M. (1985): "The Pleistocene deposit of Rebibia Cassal de'Pazzi (Rome-Italy)”. In C. Malone and S. Stoddart (eds.): Papers in Italian Archeology IV Part; The Human landscape. BAR International Series, 243: 69-85. 
Belli, G.; Belluomi, G.; Cassoli, P.F.; Cecchi, S.; Cucarzi, M.; Deliatala, L.; Fornaciari, G.; Mallegni, F.; Piperno, M.; Segre, A.G. y Segre Naldini, E. (1991): "Découverte d'un femur humain acheuléen à Notarchirico (Venosa, Basilicate)". L'Anthropologie, 95: 47-88.

Belluomi, G. (1985): "Risultati e prospective di un nuovo metodo di datazione basta sulla racemizazione degli amino-acidi". Contributi del Centro Linceo Interdisciplinare di Sc. Nat. e loro applicacioni, 69: 135-171.

Berthelet, A.; Boisaubert, J. y Chavaillon, J. (1992): "Le Paléolithique en République de Djibouti: nouvelles recherches". Bulletin de la Société Prehistorique Française, 89 (8): 238-246.

Biddittu, I.; Cassoli, P.F.; Radicati di Brozolo, F.; Segre, A.G.; Segre Naldini, E. y Villa, I. (1979): “Anagni, a K-Ar dated Lower and Middle Pleistocene site, central Italy: preliminary report". Quaternaria, XXI: 53-71.

BidditTu, I. y SEgre, A.G. (1978): "Paleolitico Inferiore a Cava Pompi presso Pofi (Fronsinone)". Quaderni del Centro Studi per l'Archeologia Etrusco-Italica, 1: 77-79.

- (1982): "Pleistocene medio-superiore con industria arcaica su ciottolo nel bacino di Agnani (Lazio)". Atti della XXIII Riunione scientifica dell Istituto Italiano di Preistoria e Protostoria: 567-576.

BINFORD, L.R. (1981): Bones: Ancient Men and Modern Myths. Academic Press. New York.

- (1987): "Where there Elephant Hunters at Torralba?". In M.H. Nitecki and D.V. Nitecki (eds.): The Evolution of Human Hunting. Plenum Press. New York: 47-105.

Botella, M.C.; Vera, J.A. y Porta, J. de, (1976): "El yacimiento achelense de La Solana del Zamborino, Fonelas (Granada). Primera campaña de excavaciones". Cuadernos de Prehistoria de la Universidad de Granada, 1: 1-44.

Brunnacker, K; Jager, K.D.; Hennig, G.; Preuss, J. y GRUN, R. (1983): "Radiometrische Untersuchungen zur Datierung mitteleuropäischer Travertinvorkommen". Ethnographisch-Archäologische Zeitschrift, 24: 217-266.

BunN, H.T. (1982): Meat-eating and human evolution: Studies on the diet and subsistence patterns of PlioPleistocene hominids in East-Africa. Ph. D. diss., University of California, Berkeley, California.

ButZER, K.W. (1965): "Acheulian occupation sites at Torralba and Ambrona Spain. Their geology". Science, 150: 1718-1722.

CAllow, P. (1986): "The Saalian industries of La Cotte de St. Brelade, Jersey". In Chronostratigraphie et Facies culturels du Paléolithique inférieur et Moyen dans l'Europe du Nord-Ouest. Sociète Prehistorique Française et l'Association Française pour l'Etude du Quaternaire (Supplement au Bulletin): 129-140.

Callow, P. y Conford, J.M. (eds.) (1986): La Cotte de Saint-Brelade, 1961-1978. Geo Books. Norwich.
Cerralbo, E.. (1915): "La estación humana más antigua de Europa entre las hoy conocidas". Asociación española para el progreso de las ciencias. Sección $4^{\mathrm{a}}$, Ciencias Naturales (Conferencia 19 de junio de 1913). Vol. I, secc. 4: 197-210.

ClaRK, J.D. y HAYNES, Jr.C.V. (1970): "An elephant butchery site at Mwanganda's Village, Karonga, Malawi, and its relevance for Palaeolithic archeology". World Archaeology, 1-3: 390-411.

Crader, D.C. (1983): "Recent single-carcass bone scatters and the problem of butchery sites in the archaeological record". In J. Clutton-Brock and C. Grigson (eds.): Animals and Archaeology 1. Hunters and their Prey. BAR International Series, 163: 107141.

Cremaschi, M. y Peretto, C. (1988): "Les sols d’habitat du site paléolithique d'Isernia La Pineta (Molise, Italie Centrale)". L'Anthropologie, 92: 1017-1040.

Chavaillon, J. (1996): "Territorial organization among Plio-Pleistocen hominids." En Fiorenzo Facchini (ed.): The first humans and their cultural manifestations. Colloquia of the XIII International Congress of Prehistoric and Protohistoric Sciences. September 1996, 4. Forlí, Italia: 77-84.

Chavaillon, J.; Boisaubert, J.L.; Faure, M.; Guerin, Cl.; Ma, J.L.; Nickel, B.; Poupeau, G.; Rey, P.; y WarsaMA, S.A. (1987): "Le site de dépecage Pleistocene à Elephas recki de Barogali (République de Djibouti): Nouveaux résultats et datation". Compte Rendu de la Academie des Sciences de Paris, 305. Série II: 1259. 1266.

Chavaillon, J.; Guerin, Cl.; Boisaubert, J.L. y Coppens, Y. (1986): "Découverte d'un site de dépecage à Elephas recki, en République de Djibouti”. Compte Re.. du de la Academie des Sciences de Paris, 302. Série II (5): 243-246.

Delitala, M.C.; Fornaseri, M. y Nicoletti, M. (1983): "Datazioni argon-potassio sulla serie pleistocenica di Isernia La Pineta". Isernia La Pineta: un accampamento piu' antico di 700.000 anni. Catalogo della omonima mostra. Calderini Editore. Bologna: 65-66.

Domínguez Rodrigo, M. (1994): El origen del comportamiento humano. Tipo. Madrid.

Everden, H.F. y Curtis, G.H. (1965): "The PotassiumArgon Dating of Late Cenozoic Rocks in east Africa and Italy". Current Anthropology, 6: 343-364.

FreEmAN, L.G. (1994): "Torralba and Ambrona: A rewiew of discoveries”. In S. Corruccini and L. Russell (eds.): Integrative Paths to the Past. Paleonthropological Advances in Honor of F. Clark Howell. Prentice Hall, Englewood Cliffs. New Jersey: 597-638.

Freeman, L.G. y ButZer, K.W. (1966): "The acheulian station fo Torralba (Spain): A progress report". Quaternaria, VIII: 9-21.

GaudZinSKI, S. (1996): "Kärlich-Seeufer. Untersuchungen zu einer altpaläolithischen Fundstelle im Neuwie- 
der Becken (Rheiland, Deustschland)". Jahrbuch des Römisch-Germanischen Zentralmuseum, 43: 1-242.

Giusberti, G. y Peretto, C. (1991): "Evidences de la fracturation intentionnelle d'ossements animaux avec moêlle dans le gisement de 'La Pineta' de Isernia (Molise), Italie'. L'Anthropologie, 95: 765-778.

Goren Inbar, N; Belitzky, S.; Verosub, K.; Werker, E.; Kislev, M.; Heimann, A.; Carmi, I. y Rosenfeld, A. (1992): "New discoveries at the Middle Pleistocen Acheulian site of Gesher BenotYa'aqov, Israel". Quaternary Research, 38: 117-128.

Goren Inbar, N; Lister, A.; Werker, E. y CHech, M. (1994): "A butchered elephant skull and associated artifacts from the acheulian site of Gesher Benot Ya'aqov, Israel". Paléorient, 20 (1): 99-112.

Guidi, A. y PIPERNo, M. (1992): Italia Preistorica. RomaBari. Laterza.

HAYNES, G. (1985): "Age profiles in elephant and mamoth bone assemblages". Quaternary Research, 24: 333345.

- (1988): "Longitudinal Studies of African Elephant death and bone deposits". Journal of Archaeological Science, 15: 131-157.

- (1991): Mammoths, Mastodonts and Elephants: Biology, Behaviour and the Fossil Record. Cambridge University Press. Cambridge.

Howell, F.C. (1962): "El yacimiento de Torralba (Soria)". VII Congreso Nacional de Arqueología (Barcelona): 110-116. Zaragoza

Howell, F.C. y FreEman, L.G. (1982): "Ambrona: an early stone age site on Spanish Meseta". The L. S. B. Leakey Foundation News, 22: 11-23.

Howell, F.C.; Freeman, L.G.; Butzer, K.W. y Klein, R.G. (1995): "Observations on the Acheulian occupation site of Ambrona (Soria Province, Spain), with particular reference to recent (1980-1983) investigations and the Lower Occupation". Jahrbuch des Römisch-Germanischen Central Museum Mainz, 38: 33-82.

IsAAC, G.L.I. (1978): "The food-sharing behaviour of protohumans hominids". Scientific American, 238: 90-108.

- (1984): "The archaeology of human origins: studies of the Lower Pleistocene in East African 1971-1981". En Wendorf and A. Close (eds.): Advances in Old World Archaeology, 3. Academic Press. New York: 1-87.

KröGer, K.; Boggard, P.V den.; BittMan, F. y Turner, E. (1988): "Der Fundplatz Kärlich-Seeufer. Neve Untersuchungen zum Altpaläolithikum in Rheiland". Jahrbuch des Römisch-Germanischen Zentralmuseums Mainz, 35: 111-135.

LEAKEY, M.D. (1971): Olduvai Gorge: Excavations in Beds I and II 1960-1963. Vol. 3. Cambridge University Press. Cambridge.

Lefèvre, D; Raynal, J.P.; Vernet, G.; Pilleyre, T.; PiperNo, M.; Sanzelle, E.; Fain, J.; Miallier, D. y Mon-
TRET, M. (1994): “Sedimentation, Volcanisme et présence humaine dans le Bassin de Venosa (Basilicata, Italie) au Pléistocène Moyen: Example du site de Nortarchirico". Bulletin de la Société Prehistorique Française, 91 (2): 103-112.

MaI, D.H.; Mania, D.; Notzold, T.; Toepfer, V.; VlceK, E. y HeInRICH, W. (1983): "Bilzingsleben II". Veröffentlichungen des Landesmuseums für Vorgeschichte Halle, 36: 258.

Malatesta, A. (1978): "La serie di Torre in Pietra del Pagliaccetto e il bacino di Torre in Pietra". En A. Malatesta et alii: "Torre in Pietra. Roma.". Quaternaria, XX: 237-246.

Malatesta, A.; Jacobacci, A.; NapPI, G.; Contao, V.; Molinari, V.; Paganelli, A.; WerfF, A.VAn Der.; Settepassi, F.; Caloi, L.; Palambo, M.R.; Cassoli, P.; PIPERnO, M. y BidditTu, I. (1978): "Torre in Pietra. Roma". Quaternaria, XX: 205-577.

Mania, D.J. (1988): "Le Paléolithique ancien et moyen de la région de la Saale et de 1'Elbe, Allemagne de 1'Est". L'Antrophologie, 92 (4): 1051-1092.

MANIA, D.J.; ToEPFER, V. y VlCEK, E. (1980): "Bilzingsleben I". Veröffentlichungen des Landesmuseums für Vogerschichte in Halle, 32: 176.

MANIA, D.J. y Weber, Th. (1986): "Bilzingsleben III". Veröffentlichungen des Landesmuseums für Vorgeschichte in Halle, 39: 256.

Meléndez, B. y Aguirre, E. (1958): "Hallazgo de Elephas en la terraza Media del río Manzanares (Villaverde, Madrid)". Las Ciencias, XXIII (4): 597-605.

Movius, H.L. (1950): “A wooden spear of Third Interglacial age from Lower Saxony". Southwestern Journal of Anthropology, 6 (2): 139-142.

MülleR-BeCK, H. (1982): "Late Pleistocen man in northern Eurasia and the mammoth-steppe biome". In D.M. Hopkins, J.V. Matthews, Jr., C.E. Schweger and S.B. Young (eds.): Paleoecology of Beringia. Academic Press. New York: 329-52.

OAKLey, K.P.; Andrews, P; Keley, L.H. y Clark, J.D. (1977): "A reappraisal of the Clacton Spearpoint". Proceedings of the Prehistoric Society, 43: 13-30.

Panera Gallego, J. (1996): "Caracterización tecnomorfológica de la industria lítica del Complejo Inferior de Ambrona". Espacio, Tiempo y Forma, 9: 105-140.

Paz Graells, M. de (1897): Fauna mastológica ibérica. Real Academia de Ciencias. Madrid.

Peretto, C. (ed.) (1991): Isernia la Pineta, nuovi contributi scientifici. Isernia, Istituto regionale per gli studi storici del Molise 'V Cuoco'. Italia

- (1996): I reperti paleontologici del giacimento paleolitico di Isernia La Pineta. Isernia, Istituto regionale per gli studi storici del Molise 'V. Cuoco'. Italia

Pérez González, A. y Aleixandre Campos, T., (1995): "Aproximación a los Paleoambientes del Hombre en el Pleistoceno Medio e Inferior. Los casos de Ambrona, Torralba y Atapuerca”. En A. Pérez González y T.

T. P., 55, n. $^{\circ} 1,1998$ 
Aleixandre Campos (eds.): IX Reunión Nacional sobre el Cuaternario. Reconstrucción de Paleoambientes y Cambios climáticos. Guía de la Excursión Postreunión. Madrid, 28-30 de Septiembre 1995, 43 págs.

Pérez González, A.; Santonja, M.; Gallardo, J. y AleiXANDRe, T. (1991): "Los yacimientos pleistocénicos de Torralba y Ambrona y sus relaciones con la evolución geomorfológica del poljé de Conquezuela". Resúmenes de las Comunicaciones. VIII Reunión Nacional del Cuaternario (sin paginar). Valencia.

Pérez González, A.; Santonja, M.; Gallardo, J.; AleiXandre, T.; Sese, C.; Soto, E.; Mora, R. y Villa, P. (1997): "Los yacimientos pleistocenos de Torralba y Ambrona y sus relaciones con la evolución del poljé de Conquezuela". Geogaceta, 21: 175-178.

Piperno, M. y BidditTu, I. (1978): "Studio tipologico e interpretazione dell' industria acheuleana e pre-musteriana dei liveli (m) e (d) di Torre in Pietra". Quaternaria, XX: 297-300.

PotTs, R. (1989): “Olorgesailie: New excavations and findings in Early and Middle Pleistocene contexts Southern Kenya, Rift Valley". Journal of Human Evolution, 18: 477-484.

Radmill, A.M. y Boschian, G. (1996): Gli scavi a Castel di Guido: il più antico giacimento di cacciatori del Paleolitico inferiore nell'A gro Romano. Firenze, Italia.

Roebroeks, W. y Kolfschoten, T. van, (1994): "The earliest occupation of Europe: a short cronology". Antiquity, 68: 489-503.

Ruiz Bustos, A. (1984): "El yacimiento paleontológico de Cúllar Baza I". Investigación y Ciencia, 91: 20-28.

Ruiz Bustos, A. y Michaux, J. (1976): "Le site prehistorique noveau de Cúllar Baza I (Grenade, Espagne), d'age Pleistocène moyen. Etude preliminaire et analyse de la faune de Rongeurs". Geologie Mediterranée, III (3): 173-182.

Ruiz Bustos, A.; Toro Moyano, I.; Martín Suárez, E. y Almohalla Gallego, M. (1986): "Procesos Evolutivos durante el Cuaternario Medio y Superior en las poblaciones de pequeños mamíferos del sur de la Península Ibérica". Cuadernos de Prehistoria de la Universidad de Granada, 7: 9-35.

Rus, I. y ENAMORADO, J. (1991): "Flint supply in the Manzanares Valley: The Acheulian site of Arriaga (Madrid, Spain)". En VI Flint International Symposium (Abstracts). Instituto Tecnológico Geominero de España. Madrid: 268-271.

Rus, I. y Vega Toscano, G. (1984): "El yacimiento de Arriaga II: problemas de una definición actual de los suelos de ocupación". Primeras Jornadas de Metodología de Investigación Prehistórica, 1981. Ministerio de Cultura. Madrid: 387-404.

SAntonja, M. (1989): “Torralba y Ambrona, nuevos argumentos". Boletín del Seminario de Estudios de Arte y Arqueología, LV: 5-13.
- (1992): "La adaptación al medio en el Paleolítico Inferior de la Península Ibérica. Elementos para una reflexión". En A. Moure Romanillo (ed.): Elefantes, ciervos y ovicaprinos. Universidad de Cantabria. Santander: 37-75.

Santonja, M.; López-Martínez, N. y Pérez GonzÁlez, A. (eds.) (1980): Ocupaciones Achelenses en el Valle del Jarama. Publicaciones de la Diputación Provincial de Madrid. Madrid.

Santonja, M.; Pérez GonZÁlez, A.; Mora, R.; Villa, P.; Soto, E. y SESE, C. (1997): "Estado actual de la investigación en Ambrona y Torralba (Soria)". En Rodrigo de Balbin Behrman y Primitiva Bueno Ramírez (eds.): II Congreso de Arqueología Peninsular (Zamora, 24-27 septiembre 1996). I Paleolítico. II Neolítico, Calcolítico y Bronce. Fundación Rei Alfonso Henriques. Zamora: 51-65. ISBN 84/89981/01/9.

SANTONJA, M. y Querol, A. (1980a): "Estudio técnico y tipológico de la industria lítica del sitio de ocupación achelense de Aridos-1". En M. Santonja, N. López y A. Pérez 'González (eds.): Ocupaciones achelenses en el valle del Jarama. Publicaciones de la Diputación Provincial de Madrid. Madrid: 253-278.

- (1980b): "El sitio de ocupación achelense de Aridos2. Descripción general y estudio de la industria lítica". En M. Santonja, N. López y A. Pérez González (eds.): Ocupaciones achelenses en el valle del Jarama. Publicaciones de la Diputación Provincial de Madrid. Madrid: 297-306.

- (1980c): "Características de la ocupación humana en los suelos achelenses de la terraza de Aridos (Arganda, Madrid)". En M. Santonja, N. López y A. Pérez González (eds.): Ocupaciones achelenses en el valle del Jarama. Publicaciones de la Diputación Provincial de Madrid. Madrid: 321-336.

Santonja, M. y Villa, P. (1990): "The Lower Paleolithic of Spain and Portugal". Journal of World Prehistory, 4 (1): 45-94.

Scott, K. (1980): "Two Hunting Episodes of Middle Palaeolithic Age at La Cotte de Saint-Brelade. Jersey (Channel Islands)". World Archaeology, 12 (2): 137 152.

SevniK, J.; Hebeda, E.H.; Priem, N.A. y Verschure, R.H. (1981): "A note on approximately 730.000 year-old mammal fauna and associated human activity sites near Isernia, Central Italy". Journal of Archaeological Science, 8: 105-106.

Shipman, P. y Rose, J. (1983): "Evidence of butchery and hominid activites at Torralba and Ambrona: An evaluation using microscopic techniques". Journal of Archaeological Science, 10: 465-474.

Soto, E. (1980): "Artiodáctilos y Proboscídeos en Áridos (Arganda, Madrid)". En M. Santonja, N. López y A. Pérez González (eds.): Ocupaciones achelenses en el valle del Jarama. Publicaciones de la Diputación Provincial de Madrid. Madrid: 207-230. 
Thieme, H. y VeIL, St. (1985): "Neue Untersuchungen zum eemzeitlichen Elefanten-Jagdplatz Lehringen, Lkrs. Verden". Die Kunst N. F., 36: 11-58.

Thieme, H.; Mania, D.; URban, B. y Van Kolfschoten, T. (1993): "Schöningen (Nordharzvoland). Eine altpaläolithische Fundstelle aus dem mittleren Eiszeitalter”. Archäologisches Korrespondenzblatt, 23 (2): 147-163.

Tode, A. (1954): Mammut jäger vor 100,000 Jahren. Brunswick.
VILLA, P. (1990): “Torralba and Aridos elephant explotation in Middle Pleistocene Spain". Journal of Human Evolution, 19: 229-309.

- (1991): "Middle Pleistocen Prehistory in Southwestern Europe: The State of our Knowlegde and Ignorance". Journal of Anthropological Research, 47 (2): 193-217.

Weber, Th. y Litt, Th. (1991): "Der Waldelefantenfund von Gröbern, Kr. Gräfenhainichen. Jagdbefund oder Nekrophagie?". Archäologisches Korrespondenzblatt, 21 (1): 17-32.

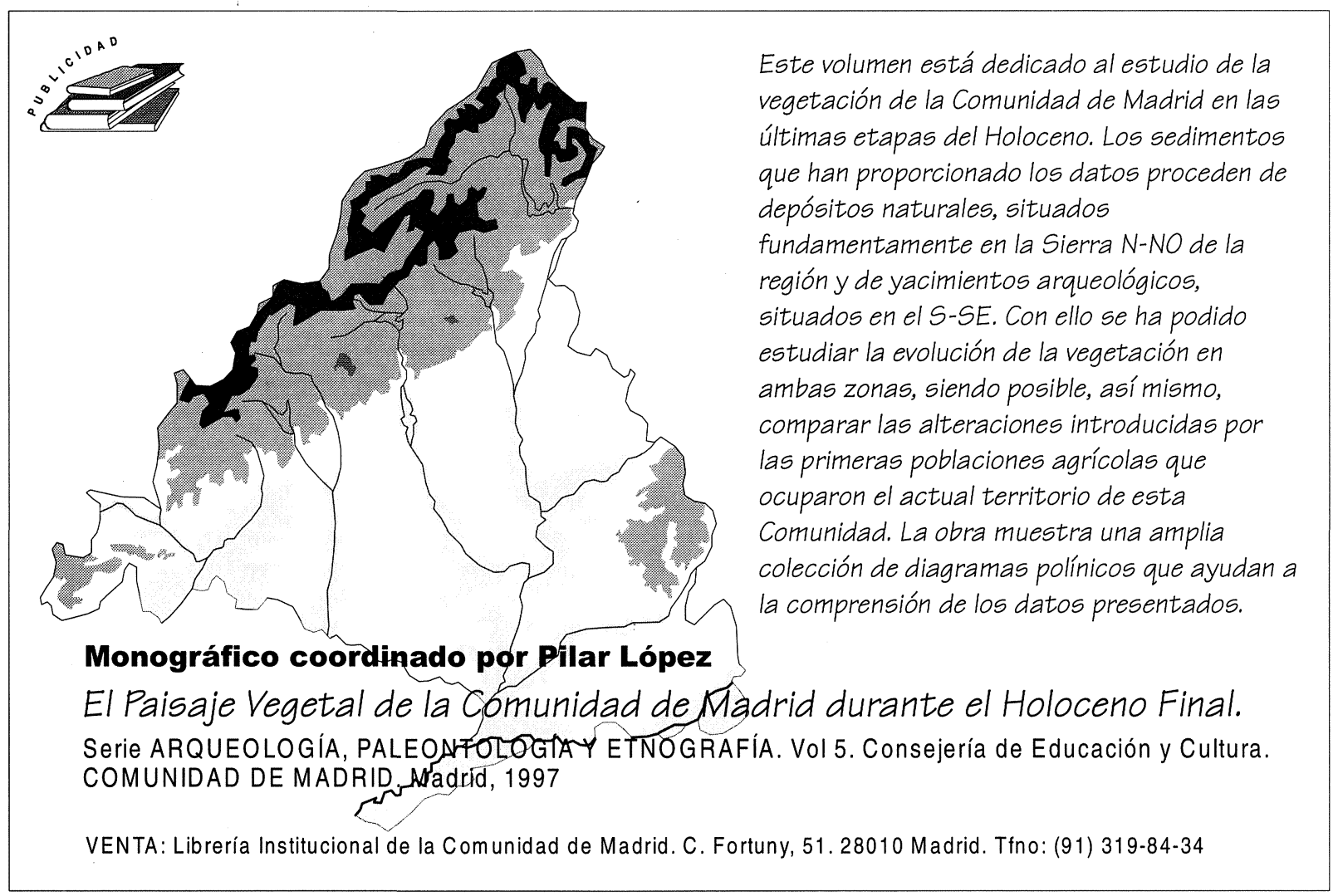

T. P., 55, n. ${ }^{\circ} 1,1998$ 